WANL-TME-211

November 21, 1962

This NOT I CE

sponsored was prepared as an account of work

the United States United States Government. Neither

Commista Unted States Atomic Energy

Commission, nor any of their employees, nor any of

meir contractors, subcontractors, or their employees,

makes any warranty, express or implied, or assumes any

legal liability or responsibility for the accuracy, com-

pleteness or usefulness of any information, apparatus,

product or process disclosed, or represents that its use

would not infringe privately owned rights.

\title{
WESTERN NEW YORK NUCLEAR RESEARCH CENTER REACTOR PROGRAM
}

Experiment No. 17 - Chopper $\times$ Modulated DC Log Preamp

Experiment No. 12 - Coaxial Cable Test

Experiment No. 13 - Insulating Circuit Board Test

Experiment No. 14 - Electrical Connector Test

Experiment No. $15-$ Solid State Diode Test

Experiment No. 16 - Magnetic Amplifier Test

Experiment No。 17 - Neutron Detectors 


\section{DISCLAIMER}

This report was prepared as an account of work sponsored by an agency of the United States Government. Neither the United States Government nor any agency Thereof, nor any of their employees, makes any warranty, express or implied, or assumes any legal liability or responsibility for the accuracy, completeness, or usefulness of any information, apparatus, product, or process disclosed, or represents that its use would not infringe privately owned rights. Reference herein to any specific commercial product, process, or service by trade name, trademark, manufacturer, or otherwise does not necessarily constitute or imply its endorsement, recommendation, or favoring by the United States Government or any agency thereof. The views and opinions of authors expressed herein do not necessarily state or reflect those of the United States Government or any agency thereof. 


\section{DISCLAIMER}

Portions of this document may be illegible in electronic image products. Images are produced from the best available original document. 


$$
\left(\sin t^{\prime} \cdot \therefore \cdot x^{\prime} \quad\right)
$$

This memorandum was compiled and edited by Mr. H. P. Kalapaca, Control Equipment Design, Control Development, WANL. Detailed test procedures were prepared by the following individuals:

Chopper Modulated DC Log Preamp - Mr. T. P. Weldon, Reactor Instrumentation $_{8}$ Control Development, WANL and Mr。D. P. Orange, Control Equipment Design, Control Development, WANL.

Coaxial Cables and Circuit Boards - Mr. T. P. Weldon, Reactor Instrumentation, Control Development, WANL。

Electrical Connectors - Mr. W. E. Blevans, Control Equipment Design, Control Development, WANL and Mr. T. P. Murray, Reactor Instru= mentation $_{g}$ Control Development, WANL.

Solid State Diodes and Magnetic Amplifiers - Bendix Corporation

Neutron Defectors $=$ Mr. W. E。 Austin, Reactor Instrumentation, Control Development WANL.

Approved:

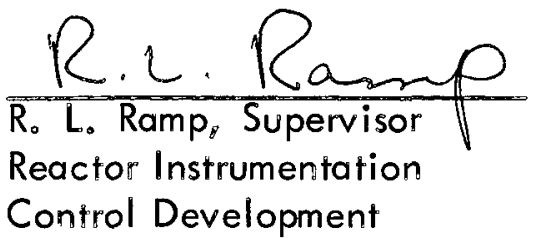

Approved:

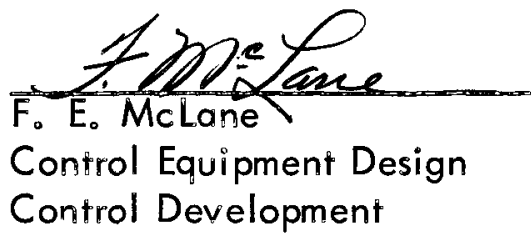

/lel 


\section{WESTERN NEW YORK NUCLEAR RESEARCH CENTER REACTOR PROGRAM}

1.0 General - The experiments described in this memorandum represent a continuation of the efforts begun in June 1962. As stated in WANL-TME -039 , dated April 14, 1962, the purpose of these experiments is to perform initial screening of electronic components and circuit assemblies presently being considered for use in the NERVA reactor control system. Thus far, ten experiments have been conducted at the WNY reactor consisting of tests on insulated wires, coaxial cables, resistors, capacitors, electronic tubes, electrical insulating coatings, pulse preamplifiers, and DC preamplifiers. The present set of experiments are scheduled to be conducted during the time period December 17 - December 21, 1962. Subsequent tests will be carried out at the Nuclear Aerospace Research Facility (NARF) in Fort Worth, Texas and at the Plum Brook Reactor Facility.

\subsection{Test Conditions}

2.1 Physical Location - All of the experiments described in this memorandum except the coaxial cable test will be placed within the $3^{\prime \prime} \times 3^{\prime \prime} \times 30$ "aluminum capsules used in prior runs. Likewise, as before, all of the experiments will be located in the $A 3$ experimental hole of the WNY reactor core. The coaxial cables will be placed within an air-filled 3" diameter standpipe which will also be located in the $A 3$ experimental hole.

2. 2 Nuclear Environment - Measurements made during the last series of tests at the WNY Facility which involved placing bare and cadmium-covered cobalt and nickel foils in the interior of the test capsules (with the experiments in place) revealed the following neutron flux data:

Fast neutron flux $(E>2.9 \mathrm{Mev})=1.2 \times 10^{12} \mathrm{n} / \mathrm{cm}^{2} \mathrm{-sec}$

Thermal (cadmium difference) neutron flux $=4 \times 10^{12} \mathrm{n} / \mathrm{cm}^{2}$-sec

These values agree very closely with independent measurements made by three other agencies in the same experimental hole.

The gamma dose information obtained with nitrous-oxide dosimeters (supplied and readout by the General Dynamics/Fort Worth Corporation) indicates that the gamma dose rate in the interior of the test capsules is slightly greater than $10^{8} \mathrm{R} / \mathrm{hr}$. This value still appears to be high by a factor of two. During the present test sequence, it is planned to measure the gamma intensities using a 4-cc graphite-electrode ionization chamber.

2.3 Test Duration - Four hours. This test duration will provide the following integrated fluxes:

Fast neutron $(E \geqslant 2.9 \mathrm{Mev})=1.7 \times 10^{16} \mathrm{n} / \mathrm{cm}^{2}$ 


$$
\begin{aligned}
& \text { Thermal neutron (cadmium difference) }=5.8 \times 10^{16} \mathrm{n} / \mathrm{cm}^{2} \\
& \text { Gamma }=2 \times 10^{8} \mathrm{R}\left(1.7 \times 10^{10} \mathrm{ergs} / \mathrm{gram}-\mathrm{C}\right)
\end{aligned}
$$

2.4 Temperature Control - As was the case in prior tests, the interior of the test capsule will be filled with dry helium gas and maintained at a static pressure of 15 psig throughout the pre-irradiation, irradiation, and post-irradiation test phases. Free convection of the helium gas will provide sufficient cooling in order to maintain component temperatures below their maximum rated values (approximately $125^{\circ} \mathrm{C}$ ). 


\section{EXPERIMENT NO. 11 - CHOPPER-MODULATED DC LOG PREAMP}

1.0 Purpose of Test - The purpose of this test is to measure the performance of a chopper modulated log preamp over a current range of $10^{-9}$ to $10^{-5}$ amperes in a radiation environment similar to that expected in NERVA.

2. 0 Justification - The power range neutron detector that is being developed for the NERVA reactor control system may generate currents in the order of $10^{-9}$ amperes at the low end of its range. This signal must be transmitted to control circuits located near the payload compartment. One method being investigated is to use a DC preamplifier direchly coupled to the output of the neutron detector. Therefore $_{\beta}$ this circuit must be capable of operating properly in a radiation environment. In previous experiments, changes have been observed in the DC preamp in so far as induced currents and drift are concerned. A DC chopper modulated preamplifier would stabilize the remote DC amplifier and at the same time would be affected very little by induced DC currents. Furthermore, removing the critical DC amplifier to the payload area by means of long cables and measuring DC by chopper modulation will eliminate the grid and leakage current and associated drift problems in previous electrometer designs tested.

\subsection{Experiment Description}

3. 1 Circuit to be Tested - The circuit that will be tested is shown in Figure $\mid I-1$. The portion within the dashed lines will be placed into the reactor for the test. Basically, the circuit is a chopper stabilized DC amplifier with a thermionic log diode in the feedback. A chopper amplifier has been constructed with radiation resistant components and coupled to a Philbrick K2X DC amplifier by means of long cables. The input to the chopper has a 100 to 1 current attenuator to help swamp out errors due to induced currents in the test signal cable. $\left(R_{1}\right.$ and $R_{2}$ of Figure $\left.\|-1\right)$.

3.2 Mechanical Arrangement - The circuit is being constructed on a $13=1 / 2 " x$ $2-5 / 8^{11} \times 1 / 16^{\prime \prime}$ plate of $1100 \cdots \mathrm{H} 14$ aluminum alloy. The components are being mounted by means of steatite insulators. The $6 \$ 12$ and 5647 tubes are mounted with an international Electronic Research Corporation tube shield type T3A-421 directly to the plate. The T3A-421 tube shield is made of aluminum and beryllium-copper materials and has a total weight of 2.1 grams. The spring:assembly of these shields had a cadmium plated finish but by means of a chemical process the cadmium finish was removed. The Bristol XF I -5400 cps chopper is being mounted with a fuse clip manufactured by Littlefuse. This clip is constructed of nickel-plated phosphor bronze. A list of materials for the electronic tubes and the Bristol XF chopper is given in Table $\|-1$ and Table $\|-2$ respectively. The capacitors used in the circuit will be the CYFM glass type manufactured by Corning 
and the resistors used will be the " $M$ " coat type manufactured by IRC. The circuit will be wired with No. 20 AWG irradiated polyoletin (Raychem Corporation) insulated wire. The leads coming from the capsule to the monitoring equipment will be No. 20 AWG wire mentioned above, except for the input leads to the K2X which will be wired with Raychem 42-178 coaxial cable. The complete circuit mounted on the plate will be coated with Dow Corning 991 silicone synthetic mica-filled varnish to reduce leakage currents.

3.3 Electrical Hook-up - The test monitoring instrumentation is shown in Figure II- 1 . A regulated Philbrick power supply $(R-100 \mathrm{~B})$ will be used for the $K 2 \mathrm{X}$ amplifier. A divider taken from the power supply will provide the 200 volts required for the DC preamp. The input current source will be a laboratory constructed device, as will be the DC filament supply and $400 \mathrm{cps}$ generator.

Temperature measurements using copper-constantan thermocouples will be made at the following points:

1. On the surface of the Bristol chopper.

2. On the surface of the 6112 electronic tube.

3. On the surface of the 5647 electronic tube.

4. On the surface of one of the aluminum plates.

5. Ambient capsule gas temperature (measured about $1-1 / 2$ inches about the surface near the top).

4.0 Test Description - Irradiation tests on the chopper stabilized log preamp will consist of: (1) a pre-irradiation test in the storage rack of the reactor, (2) a test during irradiation at various reactor power levels including periodic tests during the 4 hour run af $1 \mathrm{MW}$, and (3) a postwirradiation test in the storage rack after temperatures have cooled to ambient. All of the tests performed and data accumulated in these three steps will be identical as stated in the test procedure that follows.

4. I Test Procedure - All power supplies and equipment will be energized throughout the test. The following measurements will be made as indicated under test description:

1. Record thermocouple readings.

2. Check and record balance of amplifier by means of M6.

3. Record filament voltage (M4) and current (M5). 
4. Check and record plus and minus 300 volt power supply.

5. Record plate voltage (M1) and current (M2) of chopper amplifier.

6. Check log response through $10^{-9}$ amperes to $10^{-5}$ amperes (referred to the input) and record the output voltage $M 3$. 
TABLE $\|-1$

MATERIALS LISTS FOR SYLVANIA FRAME GRID SUBMINIATURE TUBES 6112 AND 5647*

TUBE PART

Heater Wire

Heater Wire Coating

Cathode Sleeve

Cathode Tab

Cathode Coating

Mica Spacers

Stem Leads

Stem Glass

Bulb Glass

Plate

No. 1 Grid Side Rods

No. 2 Grid Straps

No. I Grid Laterals

Support Rods

Heater Connectors

No. 1 Grid Connector

Kemet Getter

Rectangular Loop

Getter Bar

Getter Material

(Flushed)

Stabil Getter

\author{
Ring \\ Getter Material
}

(Flushed)
MATERIAL

Tungsten Coil

Alundum

220 Nickel

Dotab (Nickel Alloy)

Oxide Coating of $\mathrm{BaO} / \mathrm{SrO} / \mathrm{CaO}$

Mica .006" to .011" Coated with Magnesium Oxide

.017" Dumet Wire Tinned Exterior to Glass

Corning Type 8161

Corning Type 0120

Carbonized, Nickel Plated Steel

Molybdenum

Molybdenum

Tungsten Wire

Nickel Plated Steel

Nickel Plated Steel

Nickel

Nickel

Iron Clad Barium

Barium, Aluminum
Nickel or Nickel Plated Steel

Barium, Aluminum, Nickel

* An actual material list for these tubes was not available but because of a similarity of these tubes with other known Sylvania subminiature tubes, it is believed that the materials are essentially the same. 
TABLE $\|-2$

MATERIALS LIST FOR BRISTOL XF 1-5 400 CPS CHOPPER

Total weight of chopper 8.5 grams.

Header: Compression type construction using only 300 stainless steel pins and base. No boron oxide in glass.

Permanent Magnet: Alnico VIII with total weight of 0.68 grams.

\begin{tabular}{ccc} 
MATERIAL & PERCENTAGE OF COMPOSITION & WEIGHT \\
\cline { 1 - 3 } $\mathrm{Fe}$ & $35 \%$ & .238 grams \\
$\mathrm{Co}$ & $34 \%$ & .231 grams \\
$\mathrm{Ni}$ & $15 \%$ & .102 grams \\
$\mathrm{Al}$ & $7 \%$ & .0476 grams \\
$\mathrm{Ti}$ & $5 \%$ & .034 grams \\
$\mathrm{Cu}$ & $4 \%$ & .0272 grams
\end{tabular}


TEST CAPSULE

AUXILIARY TEST

EQUIPMENT

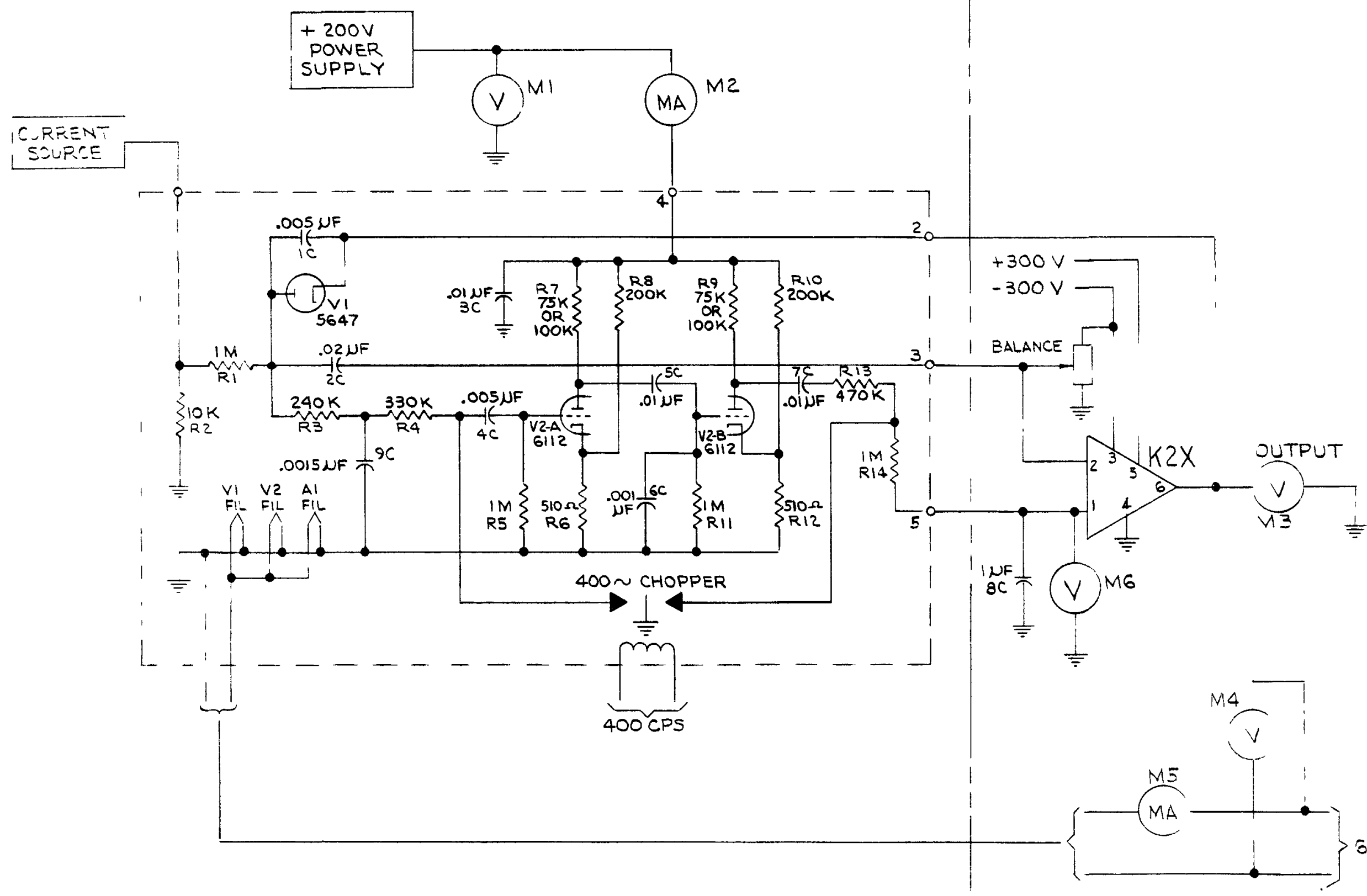

LOG MICROAMMETER AMPLIFIER

CHOPPER STABILIZED

FIGURE $11-1$ 


\section{EXPERIMENT NO. 12 - COAXIAL CABLE TEST}

1.0 Purpose of Test - It is the designed purpose of this test to measure radiation-induced effects on cables directly affecting application to neutron detectors. Induced DC currents at an applied potential in the order of microvolts will be measured with a high gain linear microammeter setup.

2.0 Test Justification - The results of the coaxial cable test conducted during the last series of experiments at the WNY (Buffalo) reactor (Refo Experiment No. 6, WANLTME-169) revealed that the RG-149/U cable exhibited the least amount of radiationinduced current. It appears that one factor which might partially account for this phenomenon is the relatively thick dielectric of the RG-149/U cable. However, since this cable uses polyethylene as a dielectric material, it cannot be used over a wide temperature range. In this respect, the irradiated polyolefin coaxial cables are much superior. The irradiated polyolefin cable tested last time had induced currents considerably higher than the RG-149/U. However, it had a much smaller dielectric thickness. In the present test ${ }_{g}$ it is planned to measure the radiation-induced currents in the largest available irradiated polyolefin cable and get a direct comparison with the same size of cable tested before.

3.0 Test Conditions - The cables tested will be subjected to the nuclear environment as described in the introduction. It is not intended, however, to test for integrated effects. Tests will be made at different levels as required to establish rate effects. Dosimetry checks will be made to establish exposure levels.

Cables will be mounted in a standpipe inserted in the reactor core. Cooling will be provided by air convection in the standpipe to the surrounding reactor coolant water. Thermocouples will be attached to the cables undergoing test to monitor temperatures.

\subsection{Experiment Description}

4. 1 Cables to be Tested - The following cables will be tested in this experiment.
a.) Raychem 22-124 (irradiated Polyolefin) 0.375" O. D.
b.) Raychem 32-195 (irradiated Polyolefin) 0.155" O. D.

4.2 Mechanical Arrangement - The cables to be tested will be installed in a standpipe for insertion in the reactor core. The cable ends will be sealed with potting compound before insertion in the standpipe and taped with fiberglass tape.

4.3 Induced DC Leakage Currents - The test circuit of Figure 12-1 will be used to measure DC Leakage currents at low applied potentials. The same cables 
as tested for noise will be tested for leakage current. The operational amplifier will serve as a high gain feedback type linear microammeter. Offset will be carefully adjusted to a minute value with the amplifier balance control. This will minimize amplifier input current requirements and reduce the potential on the cable under tests to virtually zero volts $(20$ to 100 microvolts).

The range of the linear microammeter is adjustable over a wide range as determined by the feedback network of Figure 12 2 . For best accuracy and minimum offset, the amplifier output voltage will be maintained at $I$ volt or less by selecting the proper range. Induced cable current will be determined by amplifier output voltage and the feedback resistor used,

$$
\left(I=\frac{V \text { out }}{R_{F}}\right) \text {. }
$$

5.0 Test Description - The testing will include pre-irradiation testing of each cable for leakage current as described. The standpipe will then be placed in the core or with the reactor at zero power and cables again will be tested. The reactor power will then be increased in steps to a level of $10 \mathrm{KW}, 100 \mathrm{KW}$ and $1 \mathrm{MW}$ with leakage current measurements made at each level. Similarily, post-irradiation tests will be conducted after shutdown with the standpipe removed from the core and placed in a storage rack. 


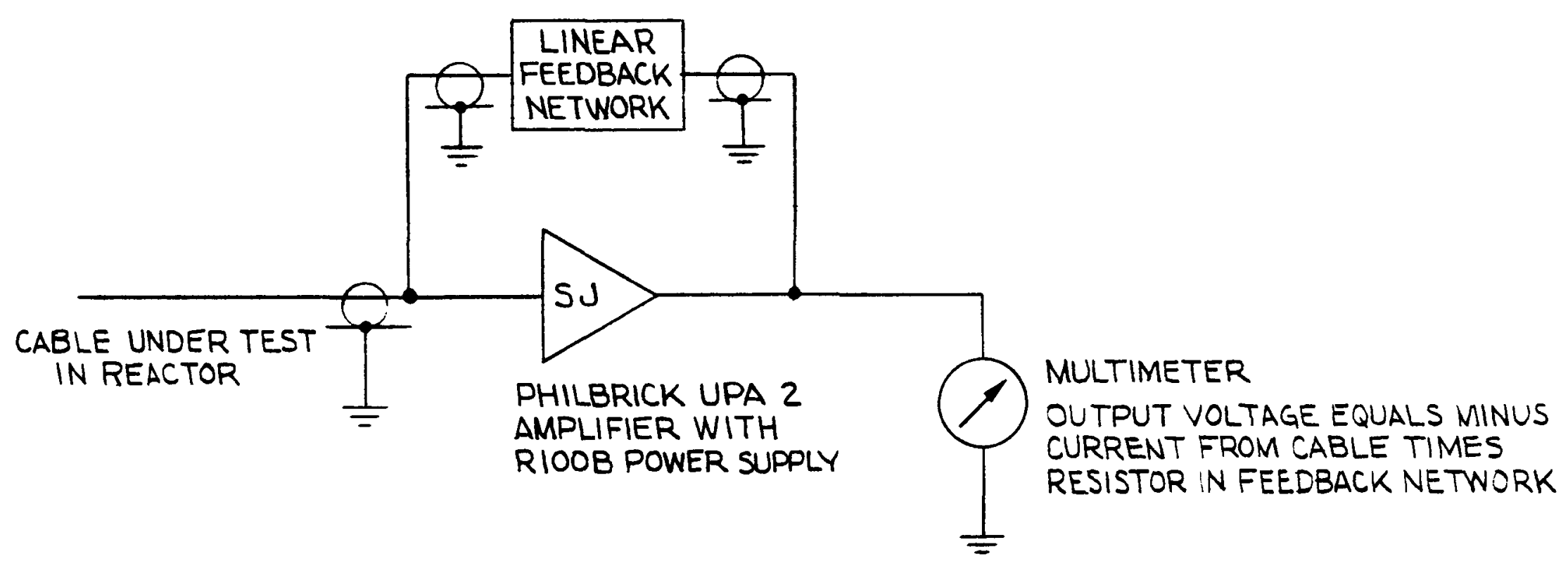

DC LEAKAGE CURRENT MEASUREMENT

FIGURE 12-1 


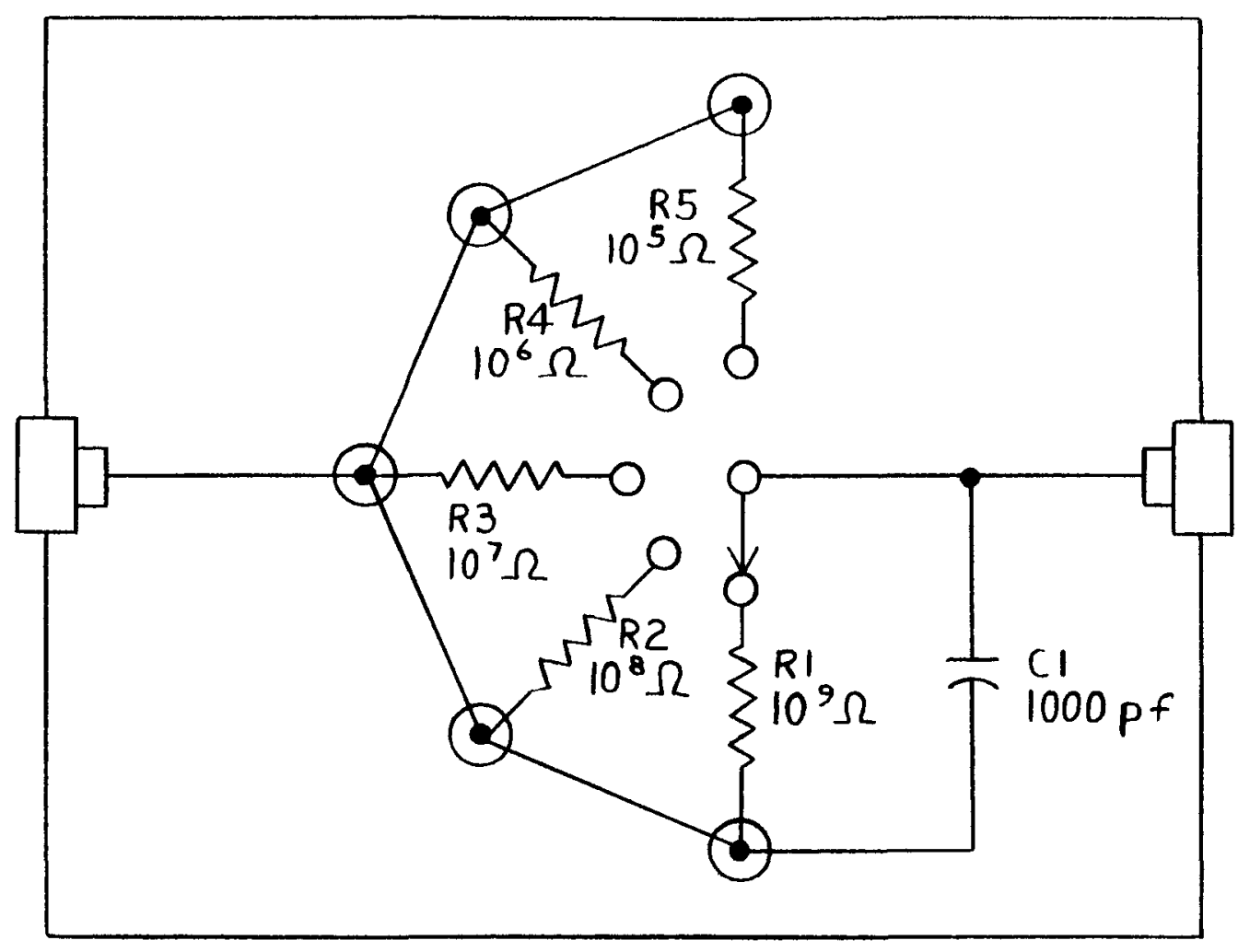

ALL RESISTORS $\pm 5 \%$

LINEAR FEEDBACK NETWORK FIGURE $12-2$ 


\section{EXPERIMENT NO. 13 - INSULATING CIRCUIT BOARD TEST}

1.0 Purpose of Test - The purpose of this test is to screen circuit packaging techniques to find the most suitable system for packaging preamplifier circuitry for NERVA applications.

2. 0 Test Justification - A review of radiation test reports has not revealed a proven packaging technique suitable for NERVA applications. A test of component parts as well as complete packaging schemes are to be screened for developing design methods suitable for NERVA applications.

\subsection{Experiment Description}

3. 1 Techniques to be Tested - The following list of circuit construction components or systems are to be tested:

1. Mycalex Corporation, Supramica 620 BB metalized circuit.

2. Corning Glass Company, Fotocerom etched circuit.

3. Westinghouse Electric Corporation, epoxy glass etched circuit.

4. Epoxylite Corporation, Epoxylite 6203 potting compound.

5. Franklin Fibre-Lamitex Corporation, Grade G-11 epoxy glass etched circuit.

6. Taylor Corporation, Type GSC silicon glass laminate.

7. Westinghouse Electric Corporation, Grade H5834 glass phenolic laminate.

8. Electralab Printed Electronics Corporation, etched circuit (fluidized epoxy with bonded copper on anodized aluminum).

9. Westinghouse Electric Aerospace Electrical Division (epoxy glass circuit on fluidized aluminum).

3.2 Mechanical Arrangement - Test samples similar to that shown in Figure 13-1 are to be mounted on standoffs on $1 / 16$ inch thick $1100-\mathrm{H} 14$ aluminum test chassis 2-5/8" wide by 13-1/2" long. Test leads of No. 20 AWG irradiated polyolefin (Raychem Corporation) will be attached to samples per Figure 13-1. Samples will be coated with Dow Corning 991 varnish filled with Mycalex synthamica to reduce surface leakage effects. 
3. 3 Electrical Hook-Up - Test leads will be wired from the test samples to the measuring equipment as shown in Figure 13-1. Insulation resistance tests as well as continuity tests through the sample conductors will be made. Test leads will be run to test equipment located on the platform above the reactor.

Measurements will be made by consecutively connecting test leads of samples to the measuring equipment.

Thermocouples (copper-constantan) will be fitted to monitor ambient temperatures as well as sample temperatures as follows:

1. Supramica test sample.

2. Epoxylite 6203 test sample.

3. Taylor silicon glass laminate.

4. Electralab etched circuit.

5. Westinghouse Aerospace Division etched circuit.

4.0 Test Description - The test will be conducted by measuring insulation resistance between the two conducting strips ${ }_{p}$ continuity of conducting strip and insulation to ground. Insulation tests will be conducted for each sample at an applied potential of $+285 \mathrm{~V}$ and -285 volts. Measurements will be conducted in the storage rack during pre-irradiation in the reactor core at zero power, at $10 \mathrm{KW}$ power, $100 \mathrm{KW}$ power and at periodic intervals during 4 hour operation at $1 \mathrm{MW}$ power level.

Post-irradiation measurements as per above will be made with the test capsule removed to the reactor storage rack. In addition post-irradiation inspection for physical damage will be conducted when access to samples is possible. 


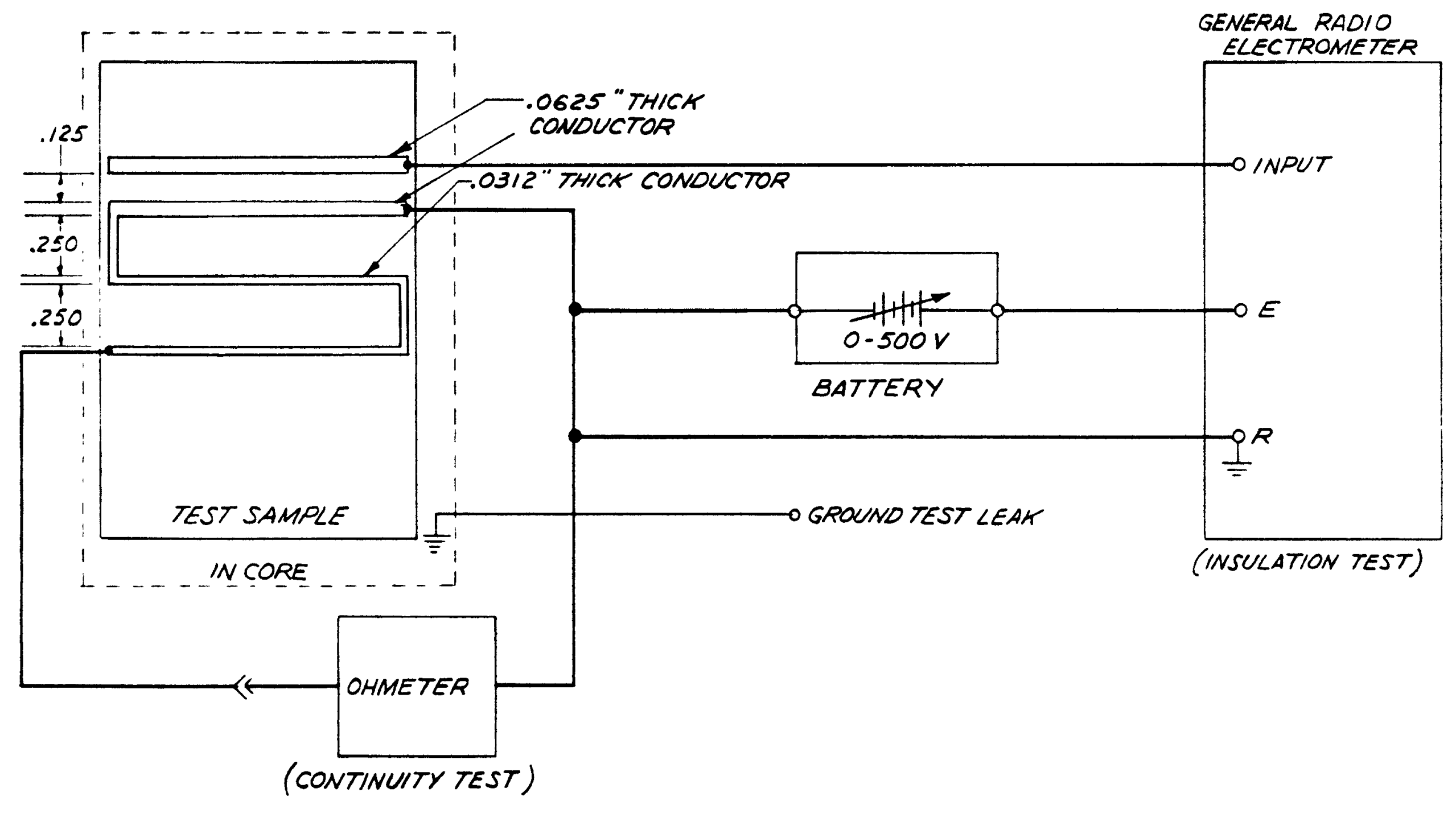

FIGURE $13-1$ 


\section{EXPERIMENT NO. 14 - ELECTRICAL CONNECTORS}

1.0 Purpose of Test - The purpose of the electrical connector test is to determine the effect of a radiation environment on the pin to pin dielectric breakdown resistance of several commonly used dielectric materials.

2.0 Test Justification - While general irradiation test information is available for several of the materials to be tested, specific information on the materials as applied in connector design is not available. This information is required prior to release of connector designs for NERVA instrumentation.

\section{0 Experiment Description}

\section{1 Connectors to be Tested}

a.) A Cole Electric Company connector containing diallyl phthalate inserts.

b.) A Physical Science Corporation connector containing Durock D-133 inserts.

c.) A Cannon Electric Company connector using alumina ceramic insulating inserts.

3.2 Mechanical Arrangement - The connectors will be mounted to heat conducting plates and/or heat conducting clips to limit the temperature of the connectors to reasonable values. The clips or plates in turn will be mounted in good contact with the 1100- H 14 aluminum alloy experiment plate.

3. 2 Electrical Hook-Up - The electrical hook-up for this test consists of a General Radio electrometer to measure the pin to pin insulation resistance (Ref. Figure 14-1). Individual pins and to the connector shell will be individually connected to the measuring setup.

4. 0 Test Procedure - The pin to pin insulation resistance will be measured at a 5 volt $\overline{\mathrm{DC}}$ potential during pre-irradiation tests, at zero reactor power, $10 \mathrm{KW}$ reactor power, $100 \mathrm{KW}$ reactor power, $1 \mathrm{MW}$ reactor power and postmirradiation. Except at the $1 \mathrm{MW}$ level, readings will be taken only once at each power setting. After the reactor power reaches the $1 \mathrm{MW}$ level, readings will be taken at $1 / 2$ hour intervals throughout the power run to measure the effect of integrated dosage. Postirradiation inspection for physical damage to the test coatings (after cooldown) will be performed for correlation with measured performance. 
TEST CAPSULE
(IN REACTOR CORE)

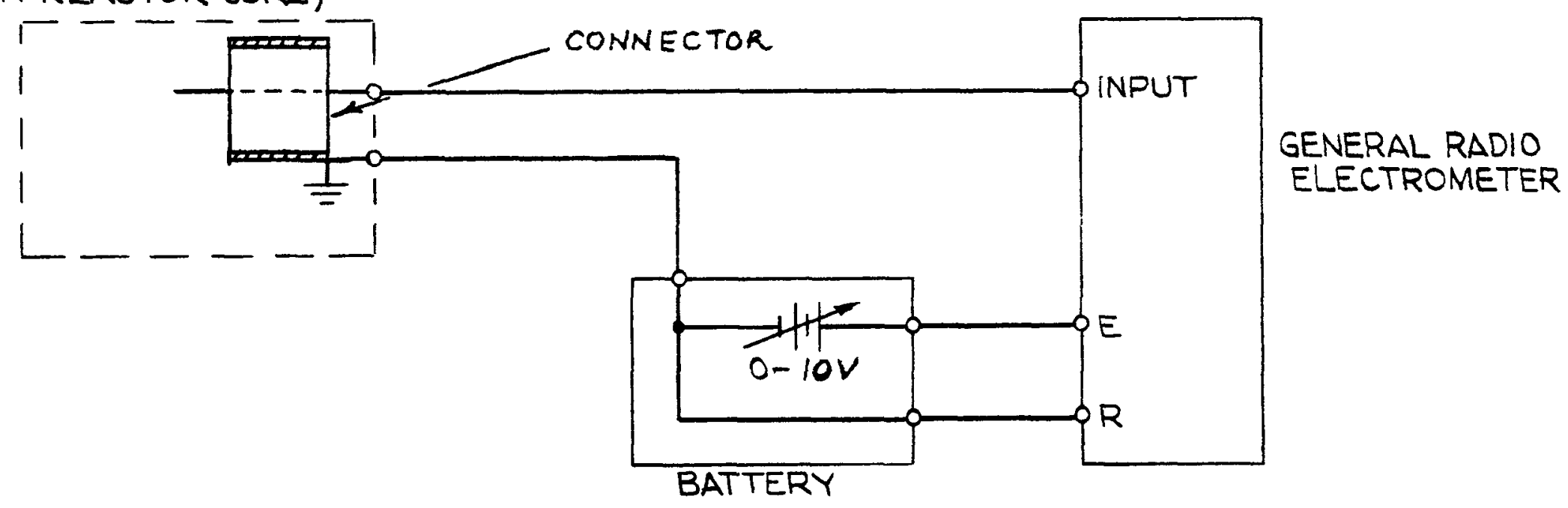

ELECTRICAL CONNECTOR TEST - ELECTRICAL HOOKUP

FIGURE 14-1 


\section{EXPERIMENT NO. 15 - SOLID STATE DIODE TEST}

1. 0 Purpose of Test - The purpose of this test is to determine the changes produced in the forward and reverse characteristics of 12 special type radiation-tolerant silicon diodes as a function of reactor radiation. These diodes are used in the magnetic amplifiers of the NERVA System and Drive Amplifiers.

2.0 Test Environment - The radiation environment is characterized by: (1) the total fast neutron dose of approximately $2 \times 10^{16} \mathrm{~cm}^{-2}$ for neutrons with energies greater than 0.1 Mev and (2) the gamma dose rate at the test location of $5 \times 10^{6}$ roentgens per hour. The thermal neutron flux should be kept to a minimum by shielding.

It is necessary to maintain a constant temperature at the test location during irradiation. This constant temperature may lie within the range of $20^{\circ} \mathrm{C}$ to $125^{\circ} \mathrm{C}$.

3. 0 Test Fixture - The reactor test fixture for mounting the 12 test devices will be fabricated by WANL. This includes the wire harness from the reactor to the test bench as well as thermocouples for monitoring the environmental temperature. The diodes should be attached to steatite standoff insulators with all of the cathodes made common. Each anode lead should be brought out separately along with the common cathode lead to the test box as per Figure 1. The hook-up wire should be of a polyolefin insulation with the conductor size approximately AWG-20 and stranded. After the diodes are mounted and electrical connections completed, the diode's leads and lead wire should be sprayed with a nonconducting acrylic or equivalent to minimize leakage currents. Two additional lines in close proximity shall be included in the harness to the test area so that leakage current measurements can be determined for the wire itself. Bendix will supply a test box for bench use containing switches and barrier terminals to which the cabling and test instrumentation can be connected. Bendix will also furnish the diodes and all test instruments with the exception of the thermocouple measurements which WANL should monitor.

\section{0 Test Material Composition}

1. Diffused silicon semiconductor.

2. Hard glass envelope.

3. Molybdenum heat sink.

5. 0 Electrical Test Procedure - During the period of irradiation, it is necessary to make $\overline{\mathrm{DC}}$ measurements of the forward voltage drop for several values of load current and record reverse leakage current at a fixed peak inverse voltage for each of the recti= fiers. In addition, a photograph of the forward and reverse characteristics should be taken for each of the devices using a Tektronix 575 curve tracer and Polaroid Land Camera. 
Referring to Figure 15-1, readings of forward voltage $V_{f}$ shall be taken for $I_{f}=$ 50, 100 and 250 ma by adjusting the series circuit resistance $R$. The forward characteristic photograph will be obtained with a maximum forward current of 250 ma. The leakage current $I_{R}$ is measured for a fixed DC potential of 100 volts. The photograph of the reverse characteristic shall be taken with an applied maximum reverse voltage of 100 volts.

All of the above measurements should be made at preradiation, at $10^{14}$ nvft, at least two reading between $10^{14}$ and $10^{15} \mathrm{nvft}$; at $10^{15}$ at least two readings between $10^{15}$ and $10^{16} \mathrm{nvft}$; at $10^{16} \mathrm{nvft}$ and at the conclusion of the test (approximately $2 \times 10^{16} \mathrm{nvft}$ ). For 12 test diodes and one control unit, this means that at each of the above measurement intervals there will be 26 photographs taken and 53 meter readings recorded. The estimated time for the accumulation of a data set is 20 minutes. Included in the above readings will be the leakage current measured between two lines of lead wire as shown in Figure 1. 


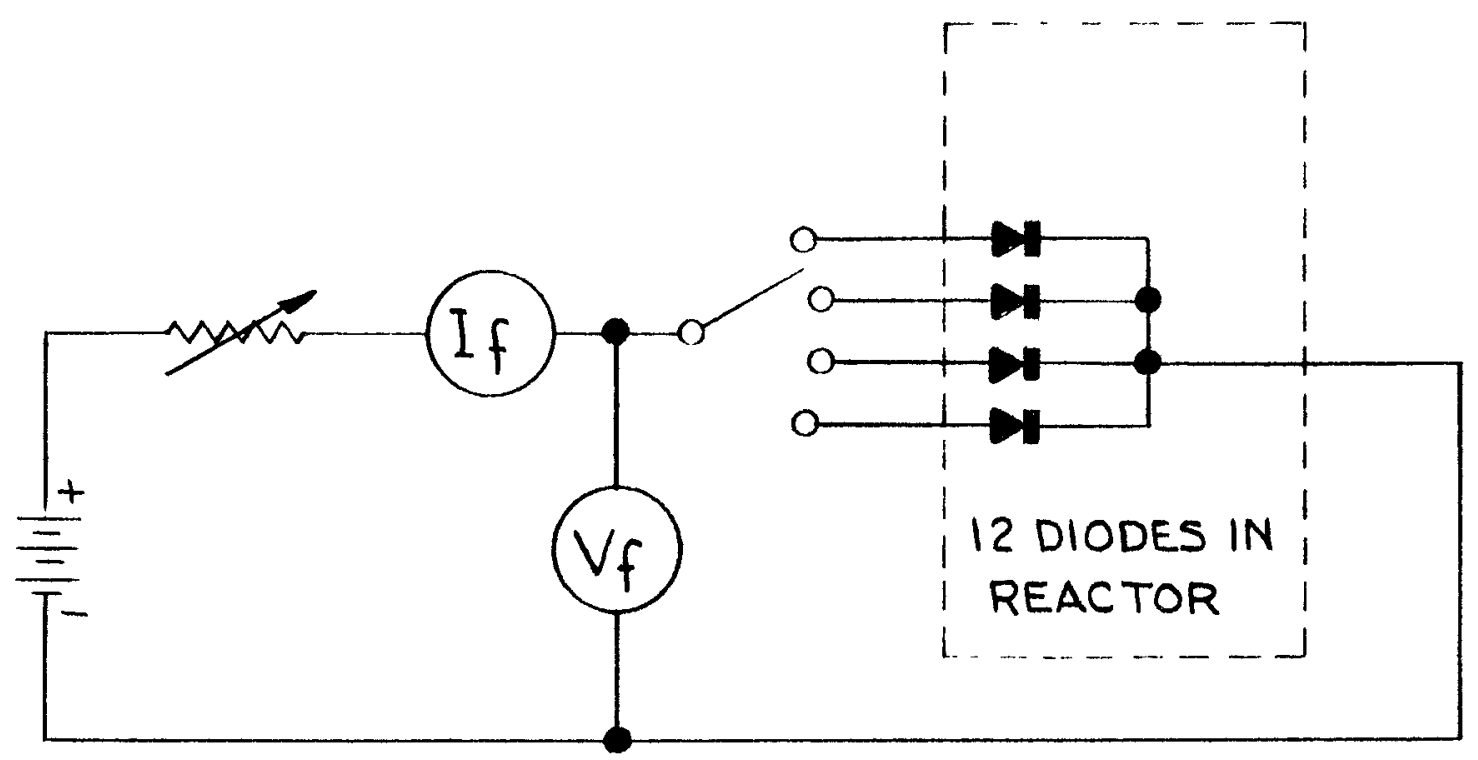

(a) FORWARD TESTS

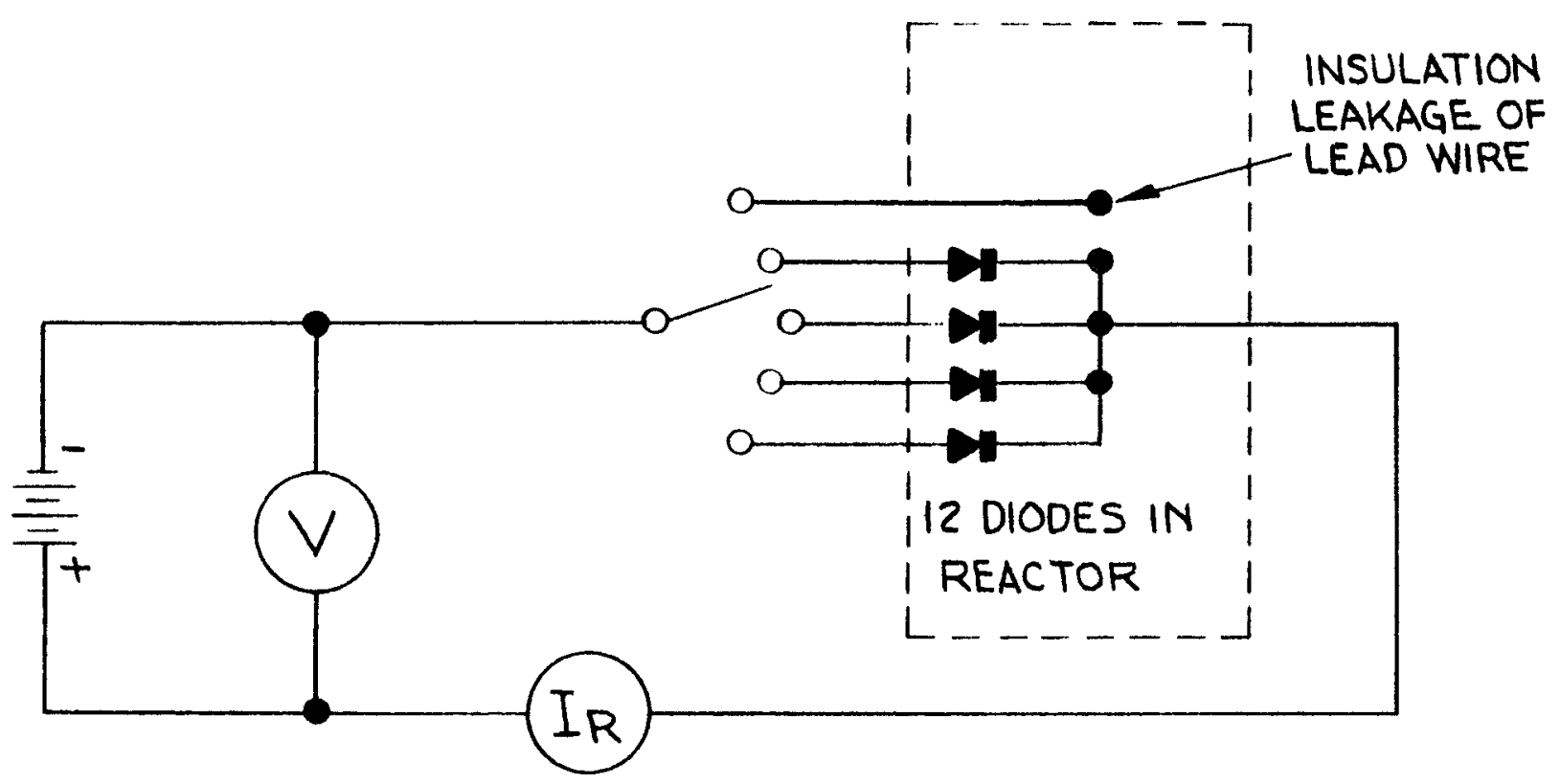

(b) REVERSE TESTS

DIODE TEST CIRCUITS

FIGURE 15-1 


\section{EXPERIMENT NO. 16 - MAGNETIC AMPLIFIER TEST}

1. 0 Purpose of Test - The purpose of this test is to evaluate the changes that may occur in the static characteristics of two typical magnetic amplifier stages as a function of reactor radiation. Gain, linearity and null shift will be observed to determine whether the compensation and balancing techniques employed are adequate for two types of cores and diodes.

2.0 Test Environment - The radiation environment is characterized by: (1) the total fast neutron dose of approximately $2 \times 10^{1} \mathrm{ncm}^{-2}$ for neutrons with energies greater than $0.1 \mathrm{Mev}$ and (2) the gamma dose rate at the test location of $5 \times 10^{6}$ roentgens/hr. The thermal neutron flux should be kept to a minimum by shielding.

It is necessary to maintain a constant temperature at the test location during irradiation. This constant temperature may be within the range of $20^{\circ} \mathrm{C}$ to $125^{\circ} \mathrm{C}$.

3. 0 Test Fixture - The reactor test fixture containing the two magnetic amplifier stages will be fabricated by Bendix, although the hardware associated with two stages are 8 cores, 8 diodes and approximately 18 resistors. The cores are stacked in pairs with an $O$. D. of 1 inch each and are mounted between a glass epoxy fiberglass terminal board $1 / 8$ inch thick and an aluminum plate for conducting heat away from the cores. Feedthrough terminals are used to make connections between the cores, diodes and resistors and for mounting purposes. The toroidal cores are fastened by a nut and bolt arrangement to a WANL $1 / 16$ " thick by $2-5 / 8$ " by $13-1 / 2$ " $1100-\mathrm{H} 14$ test chassis. The over-all height is expected to be about $2-1 / 4$ inches.

The thermocouples for monitoring the environmental temperature at the test devices as well as the wire harness from the reactor to the test bench will be fabricated by WANL. The lead wire should be a polyolefin insulation with the conductor size approximately AWG-20 and stranded. A total of 25 leads are required. These should be connected to the amplifiers as shown in Figure 16-1. After all connections have been completed, the entire assembly including terminal boards, terminals, wire and components should be carefully sprayed with a non-conducting acrylic or equivalent to minimize leakage currents. Bendix will supply the test box containing switches and barrier strips to which the cabling and test instrumentation can be connected. Bendix will also furnish filters, power supplies and all test instruments with the exception of the thermocouple measurements which WANL will monitor. WANL will supply a standard oscilloscope for amplifier waveform observations.

\subsection{Test Material Composition}

Diodes

Diffused silicon semiconductor

Hard glass envelope

Molybdenum heat sink 
Magnetic cores

4 percent molybdenum, 79 percent nickel, 17 percent iron, 8 grams total Aluminum boxes

Magnesium oxide powder filler or silicone oil filler

Copper magnet wire, ML insulation

$M L$ impregnating varnish

Resistors

Wire wound

Metal film (possibly)

Boards

Epoxy glass fiberboard, silicone impregnated

Hardware

Silver plate brass terminals

Steel bolts and nuts

5.0 Electrical Test Procedure - During the irradiation period, static characteristics of each amplifier will be recorded using an $X-Y$ plotter as shown in Figure 16-2. The output across $R_{1}, R_{2}$, and $R_{3}$ will be plotted as a function of a motor-driven reversible polarity $D C$ input. Similarly, the second stage outputs across $R_{4}, R_{5}$, and $R_{6}$ will also be plotted. Necessary switches will be provided to permit the tracing of the various respnses. A standard oscilloscope will be used to monitor the output waveforms, and whenever unusual behavior is detected, photographs will be taken using a Polaroid Land Camera.

The two amplifier stages differ in two respects, cores and diodes. One stage will utilize conventional magnetic cores using silicone oil as the damping agent and commercially available 1 N645 silicon diodes. The second stage will employ magnesium oxide filler and special radiation tolerant diodes. A duplicate set of diodes will be located in the test box on the bench, and these rectifiers will be switched into each of the amplifier circuits. This will permit the study of amplifier performance as a function of rectifier deterioration with radiation. Degradation in diode properties is certainly expected for the standard IN645 units, but not for the specially fabricated devices. As a consequence of the diode switching, a total of 12 characteristics will be plotted for every raduation data set. Photographs will be taken as required. It is estimated that approximately 30 minutes will be needed for completing measurements at each recording interval.

Data shall be accumulated at pre-radiation, at $10^{14} \mathrm{ncm}^{-2}$, at least two readings between $10^{14}$ and $10^{15} \mathrm{~nm}^{-2}$, at $10^{15} \mathrm{ncm}^{-2}$, at least two readings between $10^{13}$ 


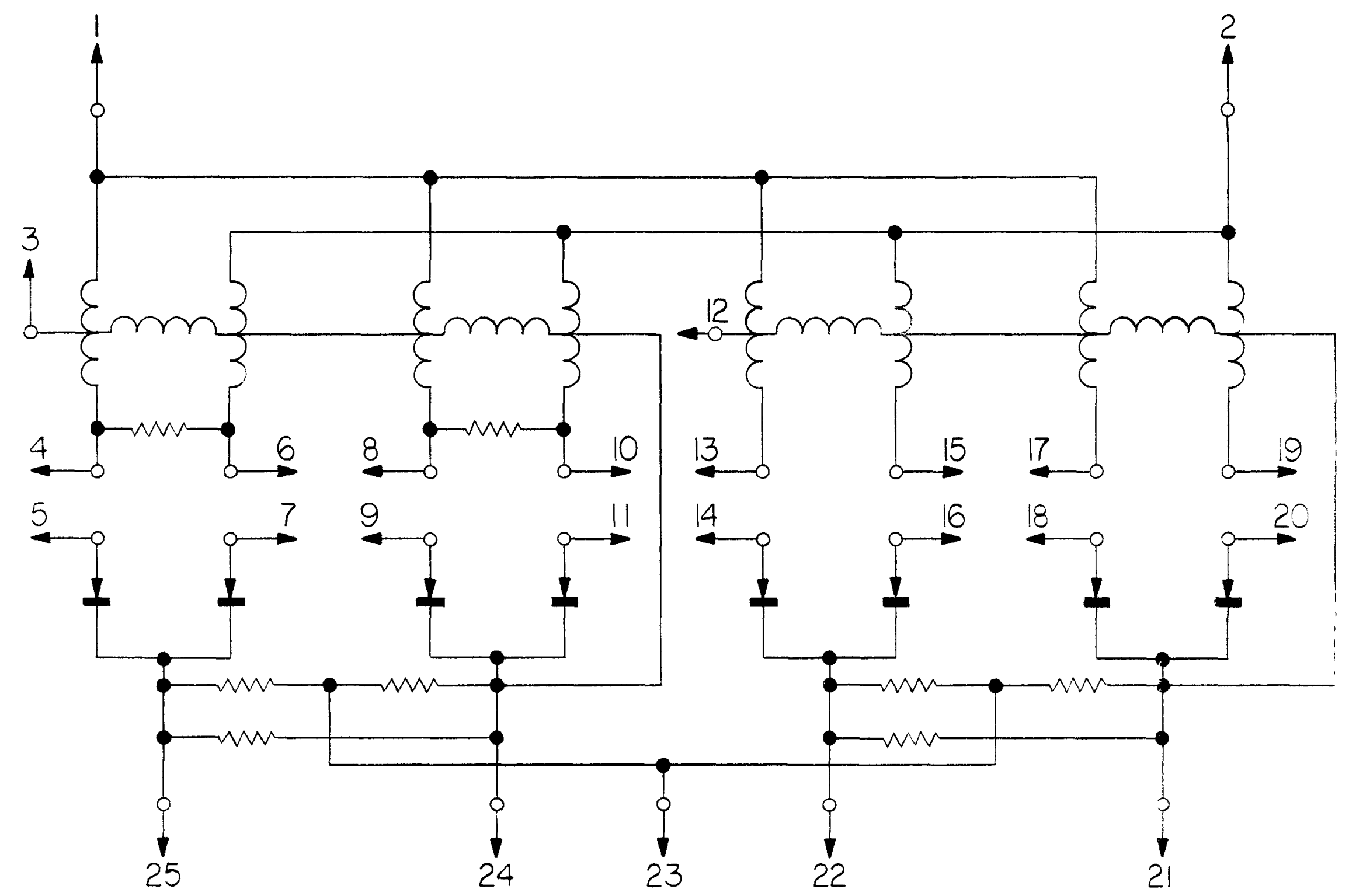

EXTERNAL CONNECTIONS TO MAGNETIC AMPLIFIERS FIGURE $16-1$ 
WANL-TME-211

and $10_{16}^{16} \mathrm{ncm}^{-2}$ at $10^{16} \mathrm{ncm}^{-2}$, and at the conclusion of the test (approximately
$2 \times 10^{1 \mathrm{ncm}^{\prime}}$ ). 


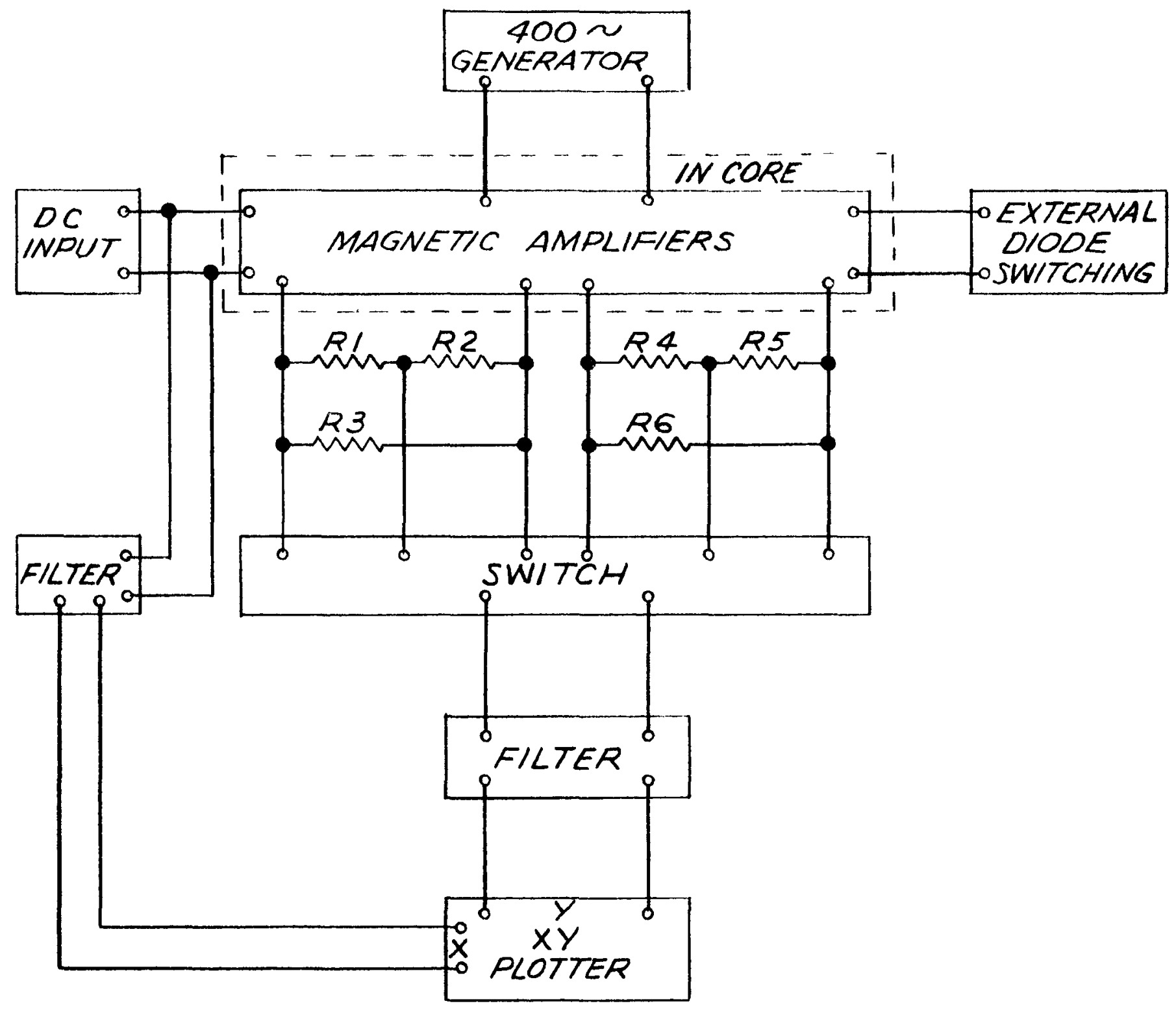

AMPLIFIER TEST ARRANGEMENT

FIGURE $16-2$ 


\section{EXPERIMENT NO. 17 - NEUTRON DETECTORS}

1.0 Purpose of Test - The purpose of the test is to establish performance characteristics of test models of neutron detectors to develop the design philosophy for final NERVA nuclear detectors.

2.0 Test Justification - The detectors to be tested are new designs which have not been tested previously. Experimental testing is required to establish confirmation of the design theory and application parameters.

3.0 Experiment Description - Two types of detectors are to be tested, both of which were designed and constructed at WANL. One is a gamma compensated ionization chamber, and the other is a pulse fission counter.

\subsection{Test Description}

\section{1 Ionization Chamber}

Test No. 1 - Purpose: to determine the degree of gamma compensation.

Method: insert the detector close to the reactor core (shutdown) and determine the detector current with:

(a) positive voltage on neutron and gamma volume. negative voltage on gamma volume.

(b) positive voltage on both volumes.

(c) positive voltage on gamma volume. negative voltage on neutron and gamma volume.

(d) negative voltage on each volume.

Test No. 2 - Purpose: to determine the maximum saturable current density of the detector.

Method: insert the detector close to the operating reactor. Determine the detector current as a function of the applied (positive) voltage to the neutron volume. Change the neutron flux either by varying detector location or reactor power and repeat above. This provides enough information to determine the maximum saturable currents.

\section{2 Fission Counter}

Test No. 1 - Purpose: to determine the rise time of defector pulses. 
Method: using a cathode follower connected directly to the fission counter and a wide band amplifier, observe the fission pulses on a fast oscilloscope.

Test No. 2 - Purpose: determine the fission spectra.

Method: use a linear amplifier, discriminator, and a scaler to determine the integral spectrum. Change the differentiating time constant to values of 10T, 5T, and IT where $T$ is the electron collection time, and determine pulse height distribution under each condition.

Test No. 3 - Purpose: determine the gamma pileup effect with differentiating time constants as above.

Method: have reactor at low power to obtain a high gamma-filled and a Tow neutron flux. Take pulse height distribution with same values of time constants as above. 